\title{
The Relational Assessment of Neglected Youth (RANY): Probing the Need for an Assessment Tool
}

Corrine Dale, $\mathrm{PhD}, \mathrm{LPC}$

Enculture Institute of Research and Program Development, St. Louis, Missouri, United States

(iD) https://orcid.org/0000-0002-6547-7833

Contact: corrinedale@sbcglobal.net

\section{Abstract}

While child neglect is the most substantiated form of child maltreatment, there is a lack of assessment tools leading to effective treatment, particularly among older victims of neglect. To date, the research has focused on younger victims and the subsequent disruption in the attachment relationship. Although development of child neglect assessment tools has been pioneered by an ecological model, the relational nature of this type of maltreatment also necessitates an assessment of relational factors that are highly correlated to child neglect. Because neglect occurs within the caregiver relationship, assessment of interpersonal impairments among older youth can best be guided by relational cultural theory, which postulates people grow and develop through relationships. Accordingly, the Relational Assessment of Neglected Youth (RANY) is a proposed assessment tool aimed at identifying the foundational elements of neglect, the incongruence between neglect and relational growth and development, and the psychological impact of neglect. The development of the RANY depends heavily on the identification of interpersonal elements and is driven by the need for youth and caregiver input. This article constructs a case for the development of the RANY, which proposes to fill the gap in assessment of older victims of neglect and the resultant relational and psychological impairment.

Keywords: child neglect; child neglect assessment; older neglected youth; relational assessment; relational cultural theory; child neglect and older youth; child maltreatment; child abuse and neglect.

Date Submitted: April 29, 2020 | Date Published: October 15, 2020

\section{Recommended Citation}

Dale, C., (2020). The Relational Assessment of Neglected Youth (RANY): Probing the need for an assessment tool. Journal of Social, Behavioral, and Health Sciences, 14(1), 244-253. https://doi.org/10.5590/JSBHS.2020.14.1.17

\section{Introduction}

Beginning with the modern era of child protection legislation, child neglect historically has been a difficult and complex entity to assess and treat (Stowman \& Donohue, 2005). In 2004, child neglect represented 60\% of child maltreatment reports (Bundy-Fazioli \& Delong Hamilton, 2013; Dale, 2017). In the United States, in 2010, the rate of child neglect reports had risen to $78 \%$; physical abuse, at $18 \%$ of reports, ran a distant second (Bundy-Fazioli \& Delong Hamilton; U.S. Department of Health \& Human Services, 2012; Dale). By 2016, 75\% of reported victims were neglected, $17.0 \%$ were physically abused, and $8.3 \%$ were sexually abused (Child

Note: The author has no conflict of interest to disclose. Correspondence concerning this article should be addressed to Corrine Dale, Enculture Institute of Research and Program Development, 1408 Farmview, St. Louis, MO, 63138. 
Welfare Information Gateway, 2018b; Dale). While the rate of reported child neglect has remained high over the last 20 years, research focusing on this type of maltreatment has lagged behind that examining physical and sexual abuse (Dale). Because of its intractable nature, child neglect continues to be a public health concern that requires validated assessment and treatment protocols. The basic definition of child neglect is the parent's or caretaker's failure to act, resulting in death or serious physical or emotional harm necessitating an assessment of how the acts of omission affect the child's relational, social, and psychological functioning (Dale; Stowman \& Donohue). Not only does child neglect require a differential pathway to understanding its social, relational, and psychological impact, it demands more attention as the most often reported and substantiated form of child maltreatment (Child Welfare Information Gateway, 2018a, 2018b; National Children's Allinace, 2018).

This is especially the case among older youth, who are often a forgotten population in regard to child neglect assessment tools and subsequent treatment (Naughton et al., 2017). The focus to date has been on younger children and the attachment disruptions that have proven to be a result of neglect (Naughton et al.; Raws, 2018). A review of the few studies on older neglected youth reveals an absence of assessment tools focused on the relational nature of the neglect (Naughton et al.; Raws; Hicks \& Stein, 2015). The lack of an assessment instrument that identifies the self-reported social, relational, and psychological impairment experienced by older victims of neglect is a human service concern that guides this discussion. Development of an assessment instrument for older neglected youth is led by the hypothesis that acts of omission, as opposed to child abuse, which often consists of acts of commission (Stowman \& Donohue, 2005), require a relational approach to assessment and treatment. Thus, this article is piloted by an analysis of relational deficiency leading to a basis for the development of a new assessment instrument aimed at identifying and treating the social, relational, and psychological impairments among older neglected youth.

The development of the Relational Assessment of Neglected Youth (RANY) is framed by the most reported forms of child neglect, which include physical neglect, medical neglect, educational neglect, and emotional neglect. Although these forms of neglect affect physical, cognitive, and academic development, of importance to the assessment development is the relational nature of neglect and its detrimental impact on youth/caregiver, youth/peer, and youth/community relationships (Children's Services Practice Notes, 2013). Exposure to neglect can be just as traumatic as exposure to physical or sexual abuse; thus, researchers have recommended a relational trauma-based approach to treating child neglect (Banks, 2006; Children's Services Practice Notes). Conversely, before efficacious treatment can occur, it is necessary to develop an assessment tool that is based on the relational nature of neglect. Propositionally, effective implementation of relationalbased assessment begins with a tool that differentiates neglect type, frequency, and severity and that assesses relational, social, and psychological impairment. Accordingly, presentation of a model for this type of assessment tool requires a foundational review of relational cultural theory and child neglect.

\section{Relational Cultural Theory, Youth, and Child Neglect}

The basic tenet of relational cultural theory is that people grow and develop through relationships (Jordan, 2001). When a lack of mutual exchanges and empathetic responses stifles relational growth, disconnection and isolation occur. The theory explains that the destruction of relationships most hinders recovery and healing (Banks, 2006; Comstock et al., 2008; Jordan, 2010). In effect, in cases of child neglect, the lack of relational experiences negatively impacts healthy growth and development (Dale, 2017). Additionally, neglected children begin with a distorted view of relationships that, as they grow older, results in withdrawal, social isolation, and interpersonal problems (Becker-Weidman, 2009; Children's Services Practice Notes, 2013). This distortion also reflects a view of relationships that includes a longing for connection combined with a fear of being hurt again or the relational paradox (Jordan, 2001, 2010). In neglected older youth, this may display as poor peer interaction, academic failures due to lack of connection to educators, and relational 
representation that equates treatment of this type, "the absence of," with normalcy (Hicks \& Stein, 2015). This type of distortion can be addressed first through proper assessment, followed by a provision of relational trauma-based interventions.

Birrell and Freyd (2006), in a definition of betrayal trauma, advance that this "violation" inherently exists in the relationships that lead to a form of isolation and disconnection that may make individuals feel locked out of the possibility of human connection. This can be seen in the violations experienced by older youth who are better able to process the betrayal as one that impairs their ability to connect and engage in empathetic exchanges with others (Naughton et al., 2017). While traditional growth and development theories see the older youth as attempting to differentiate through less dependence on caretakers and more emphasis on peer relationships (i.e., Erikson), relational cultural theory sees the older youth as in need of mutual growthproducing opportunities not only between the youth and caretaker, but between the youth, other adults, and community, as well as same-age peers. The idea that older youth may no longer need relational care by the caregiver is misguided and lays a foundation for more severe forms of neglect among this often-isolated population.

Older neglected youth are also becoming aware of social transgressions, such as truancy and peer group rejection, and are at an age in which cultural/social elements such as cultural awareness and physical attraction are acknowledged and analyzed (Rivas-Drake et al., 2014). Identifying and assessing the cultural/social disconnection can lead to an understanding of why one may be disruptive in school as well as an understanding of dysfunctional family, peer, and community relationships. Among therapeutic approaches, relational-based interventions treat these types of disconnections through identification, evaluation, and rewiring of relational images that may have resulted in the disconnection that was a contributor to social violations and withdrawal. I contend here that the understanding that healthy connections begin with empathetic exchanges and mutuality reinforces the need for an assessment tool of older neglected youth.

\section{Relational Trauma, Older Youth, and Child Neglect}

Traditionally the attachment relationship is considered the foundation and guide for relational development and has led to neglect research that focuses primarily on young victims (Naughton et al., 2017; Raws, 2018). Yet, development of a relational assessment tool like the RANY can enhance our understanding of the impact of childhood attachment and relational disconnection on older neglected youth. Beginning in infancy and continuing into adulthood, the establishment of early attachment relationships is required for positive trajectories for those exposed to child neglect; however, late-onset neglect can also be treated through the reestablishment of relational connection. Among older youth, neglect research has mostly focused on the form of neglect, which includes a lack of supervision that has led to social violations, as seen in juvenile delinquency (Cashmore, 2011; Evans \& Burton, 2013). Essentially, the absence of research on the psychological consequences of impaired caregiver relationships among older neglected youth leads to the call for a tool like the RANY.

While there are very few studies that examine the impact of child neglect on older victims, Hicks and Stein's 2015 study reported that $13 \%$ of all 13- to 17-year-olds experience neglect. Striving to address the gap in knowledge regarding older victims of child neglect, they reviewed national and international research on adolescent neglect. The researchers attempted to develop an understanding of adolescent neglect from the perspectives of young people and multi-agency staff who work with youth exposed to victimization (Hicks \& Stein). The study revealed that youth described neglect as an absence of caring parental responsibility, e.g., "no love and affection" and being "blamed for break-up in relationships." Notably, the adolescents considered parents neglectful if they did not teach their children basic social skills, morals, manners, and how to look 
after themselves (Hicks \& Stein). Another study involving adolescents found that the young people in the group offered descriptions of neglect that included phrases such as: "not enough love"; "parents and stepparents having no interest in me"; "having to look after brothers and sisters-you end up doing your parents job," and "the responsibility is passed to you"; and "parents neglect themselves" (Daniel et al., 2014). These definitions reflect the absence of mutual and empathetic growth-producing opportunities that are necessary experiences in the development of socially connected and psychologically healthy adults.

Research supports the view that, as opposed to the more dire forecast for younger victims exposed to severe child neglect and subsequent attachment disruption, neglect among older youth results in disconnections that can be repaired if adequately assessed and treated (Daniel et al., 2014; Hicks \& Stein, 2015; Jordan, 2001). Li and Julian (2012) offer a more optimistic view of attachment through an allusion to what they term emotional attachment, which like relational development, requires reciprocal engagement and can occur with any adult, not just the primary caregiver. The RANY offers an avenue of vital assessment leading to a form of treatment that can guide relational repairment.

\section{Elements of Child Neglect and the RANY}

Research shows that child neglect victims have deficits in health and physical development that include impaired brain development, delays in growth or failure to thrive; intellectual and cognitive deficits, which include poor academic performance and delayed or impaired language development; deficits in emotional and psychological development, including deficiencies in self-esteem, attachment, or trust; and gaps in social and behavioral development, which include interpersonal relationship problems, social withdrawal, and poor impulse control (Child Welfare Information Gateway (2018a). Most of these deficits, such as failure to thrive or impaired language development, refer to assessment in younger children leaving a need for relational and psychological assessment in older neglect victims. The RANY will address this gap by focusing on victims ranging in age from 10 to 17 . Infants and young children are clearly vulnerable to neglect, and increasing evidence shows that children's early brain development and socio-emotional and cognitive development can be severely compromised by inadequate or harmful parenting; however, the "window" does not close; there are other peak periods of both significant brain development and increased risk-beginning in early adolescence and continuing through adolescence to early adulthood (Cashmore, 2011). This is also the period in which reciprocal relationships are vital and the absence of relational growth-producing opportunities results in impaired relational images and a form of disconnection that leads to social and psychological impairment (Naughton et al., 2017).

Researchers found sufficient evidence to suggest that neglect and/or neglectful parenting of young people (i.e., older youth) is/are associated with poor mental health and emotional well-being; risky health behaviors; risks to safety, including running away; poor conduct and achievement at school; and the likelihood of involvement in offending and antisocial behavior (Daniel et al., 2014; Hicks \& Stein, 2015). This review shows that older victims of neglect are more impacted by relational deficits leading to disconnecting behavior that is reflected in mental health problems as well as social violations. While this review of the perception of child neglect among older youth contributes to an understanding of the child neglect literature, we must also examine within the context that it is multifaceted, encompassing perpetrator, social, community, familial, and generational factors, or within the context of an ecological model (Child Welfare Information Gateway, 2018a; Stowman \& Donohue, 2005). The RANY provides this context through its five assessment categories-child neglect elements, quality of relationships, relational images, social/cultural connectors, and psychological disorders.

Stowman and Donohue (2005) maintained that relative to child physical abuse, child neglect is more strongly associated with poverty, few social networks, single parenthood, and parental age under 30 . They emphasized 
the environmental constraints of limited emotional and financial resources and concluded that characteristics that are typically identified as being related to child neglect include single parenthood, economic hardship, lack of social support, strained parent-child interactions, mental health issues, substance abuse, and domestic violence (Stowman \& Donohue). Conceptionally, while these elements impact some forms of growth and development, in particular in younger children, older children are more impacted by the absence of relational mutuality leading to a form of disconnection that impacts interpersonal, social, and psychological functioning.

\section{Components of Assessment Instruments of Neglect}

Researchers have found it difficult to develop assessment instruments for neglect because it is the absence rather than the presence of something (Child Welfare Information Gateway, 2018a). Some have found that strength-based assessments of older youth should include an analysis of impairment in school and social and psychological functioning (Hicks \& Stein, 2015). Others have suggested that the nature of child neglect calls for assessment instruments and interventions that include an ecological analysis, in collaboration with the parent, that reviews the child's safety and risk and protective factors (Child Welfare Information Gateway, 2018a). Yet, this again mostly reflects the needs of younger victims of child neglect (Child Maltreatment, 2016). I propose here that older victims of child neglect are underexposed to relational opportunities, which results in impaired or delayed relational growth and development. In fact, I hypothesize that the absence of growth-producing relationships is the most devasting and impairing component of child neglect. With an understanding that over $90 \%$ of child maltreatment is committed by those related to the victim (National Statistics on Child Abuse, 2018), I maintain that the absence of relational growth-producing opportunities among older neglected youth can lead to a subpopulation of socially and psychologically disconnected victims.

Today, development of effective assessment begins with a theoretical base that encompasses a strength-based approach. In regard to relational cultural theory, this refers to the establishment of the five good things of a growth fostering relationship. These include (1) an increased sense of energy or zest within the relationship; (2) each person within the relationship feels an increased ability to act and does act; (3) each person within the relationship has a greater sense of worth; (4) each person in the relationship has a greater clarity about herself, the other, and the relationship; and (5) each person within the relationship has an increased desire for more connections outside of the relationship (Banks, 2006; Comstock et al., 2008). Thus, as framed by relational cultural theory, the assessment instrument should include the assessment of relationships, the level of connection, as well as the level of social and psychological impairment. In other words, it is formulated that the RANY will include a parent and child version, will result in identification of relational images and social/cultural connectors. It will guide relational treatment of psychological disorders such as Substance Abuse, PTSD, Dissociative Reality, Depression, and Anxiety, which will begin to address Sen et al.'s (2014) contention that the biggest gap in evidence in respect to child neglect is the lack of parents' and children's views. Indeed, the RANY is advanced as a pathway to treatment that infuses victims with the five good things of a growth-fostering relationship.

\section{RANY Versus Current Assessment Instruments}

Overall, any instrument measuring the impact of neglect must be age specific and assess severity, frequency and duration, type of child neglect, age of the child, and potential consequences to the child's development (Sen et al., 2014). The literature reveals several instruments for assessing neglect, beginning with the Ontario Child Neglect Index (CNI), which provides child welfare practitioners and researchers with a validated method of specifying the type and severity of neglect. The CNI is a one-page index with six neglect scales (i.e., supervision, nutrition, clothing and hygiene, physical health care, mental health care, and development/educational care), utilizing a four- to five-level severity rating (i.e., adequate, inconsistent, inadequate, seriously inadequate) (Sen 
et al.). Another measure of neglect includes an environmental assessment instrument such as the HAPI, which was developed in an attempt to assess the safety of home environments of families identified as abusive and or neglectful (Sen et al.). However, the need continues for a holistic instrument that includes screening of psychological disorders.

The premier behavioral scale assessing neglect is the Child Well Being Scales (CWBS), which consists of 43 scales and three subscales (child neglect, parenting skills, and child functioning relative to school performance and juvenile delinquency) used in the identification of family problems. The CWBS focuses on children, especially those at risk or in placement situations. The age range is 1 to 45 but it is especially effective with identifying problems in families with adolescents (Gaudin et al., 1992; Lyons et al., 1999; Magura \& Moses, 1986). Testing of the subscales indicates that three factors-household adequacy (10 scales), parental disposition (14 scales, including measures of parenting skills, disabilities, problem recognition, motivation, and adult/child relationships), and child performance (4 scales)-accounted for $43 \%$ of the variance (Magura \& Moses). However, criticisms of CWBS include the lack of practical experience and cultural diversity in the sample used to judge the seriousness scores and the lack of empirical evidence for validity. Based on the research, Lyons et al. cautioned against using the scales for case or clinical decision making. While this caution was against sole dependence upon the score, rather than upon use of the scales as part of a thorough assessment (Lyons et al.), it acts as a starting point to address the gap in assessment of psychological, social, and relational functioning among older victims of child neglect.

In the development of the RANY, I hypothesized that among youth exposed to child neglect, the duration, severity, frequency, and type of child neglect guides the accumulation of data leading to an assessment of disconnecting, isolating, enmeshed, and connecting relational images. These images in turn impact peer, caregiver, and other adult supervisors, such as teacher/child, and relational quality. Identification of relational impairment is expected to guide treatment that enhances community and social connections and that results in psychological health. Therefore, the RANY consists of the following:

Table1: Relational Assessment of Neglected Youth-Child Version

\begin{tabular}{lllll}
\hline Child Neglect & Relationships & $\begin{array}{l}\text { Relational } \\
\text { Images }\end{array}$ & $\begin{array}{l}\text { Social/Cultural } \\
\text { Connectors }\end{array}$ & $\begin{array}{l}\text { Psychological } \\
\text { Disorders }\end{array}$ \\
\hline Type of Neglect & Peer & Connecting & Social Connectors & Substance Abuse \\
Duration & Parent/Caregiver & Enmeshed & Cultural Connectors & PTSD/Anxiety \\
Frequency & Teacher & Isolating & Rules Violation & Dissociative Reality \\
Overall Severity & Community & Disconnecting & Economic Status & Depression \\
\hline
\end{tabular}

Table 2: Relational Assessment of Neglected Youth-Parent Version

\begin{tabular}{lllll}
\hline Child Neglect & Relationships & $\begin{array}{l}\text { Relational } \\
\text { Images }\end{array}$ & $\begin{array}{l}\text { Social/Cultural } \\
\text { Connectors }\end{array}$ & $\begin{array}{l}\text { Psychological } \\
\text { Disorders }\end{array}$ \\
\hline Type of Neglect & Child & Connecting & Social Connectors & Substance Abuse \\
Duration & Romantic & Enmeshed & Cultural Connectors & PTSD/Anxiety \\
Frequency & Parent/Caregiver & Isolating & Rules Violation & Dissociative Reality \\
Overall Severity & Peer & Disconnecting & Economic Status & Depression \\
\hline
\end{tabular}


Beginning with the elements listed in Table 1 and Table 2, developing and validating the RANY depends heavily on the understanding of the relational nature of child neglect and the consequent impact on development of older neglected youth. I hope that this evaluation leads to the beginning of a consensus of what is needed and what is effective treatment for older neglected youth. Accordingly, the RANY is a tool that attempts to address the gap in assessment instruments leading to a relational approach to the undertreated older neglect population. On the whole, the RANY is conceived as a basis of movement towards development of a strength-based approach that includes the subsequent implementation of treatment aimed at developing positive relational images, relationships, and psychological health.

Beginning with the childhood neglect category, the RANY provides a foundation for the implementation of relational-based treatment. Each subsequent category informs the relational growth and development of youth. Thus, the RANY incorporates some known elements such as severity, duration, and frequency of the neglect with new elements such as connecting or disconnecting relational images. These images are based on the youth's view of the relational world. For example, a disconnecting image reveals a youth who views the world as a distant place, she is not able to engage in empathetic exchanges, and she has a negative view of what her caregiver can do. A connected image is evidenced by an ability for the youth to engage in selfempathy and empathy, view herself as deserving of care, and have a positive view of what her caregiver can do. Assessment of social and cultural connectors also guides the treatment of neglected youth. One who has connected images is more likely to engage in prosocial activities, avoid community disconnection, and see herself as deserving of help by adults. Relational assessment leads to a form of treatment that addresses the isolation and disconnection resulting from neglect. The RANY is a tool aimed at guiding the reestablishment of familial, social, and psychological health.

\section{Future Research}

Liddle and Carter (2015) explain that in the development and validation of an assessment instrument a number of key requirements should be met, specifically face validity, construct validity, internal reliability, external reliability, and sensitivity (Liddle \& Carter). Face validity details whether the scale appears to measure what it intends to measure. Construct validity identifies whether the scale measures what it intends to measure and whether it is norm based, which is determined by comparing the scale to an existing one. Liddle and Carter go on to explain that internal reliability indicates whether the items in the scale consistently measure the same construct, and external reliability assesses whether the scale consistently measures the same construct over time. Finally, the sensitivity of the scale indicates whether it can measure any changes or discriminate between groups (Liddle \& Carter).

Liddle and Carter (2015) maintain that for there to be a good degree of face validity, not only does the scale need to look like it measures what it intends to but there also needs to be a clearly defined theoretical construct of what is being measured. This normally entails drawing upon current theoretical understanding and additionally undertaking qualitative research in order to determine what people's perception of the construct is (Liddle \& Carter).

\section{RANY Phases}

The objective of phase one is to construct the tool, assess its internal reliability, and make any necessary adjustments. The second phase of the study examines the scale's internal reliability, construct validity, and external reliability. The internal reliability of the scale will be determined by using factor analysis with a benchmark Cronbach's alpha value set at greater than o.8. External reliability will be assessed by conducting a test-retest analysis using a Pearson's correlation with a benchmark correlation greater than $r=0.7$. The construct validity of the RANY will be tested by using the CWBS. A need for social desirability indicators will be 
assessed prior to phase two. The RANY is expected to be an effective tool that can be applied across settings and can assess multisymptomatic victims leading to efficacious treatment of a historically underserved population.

\section{Conclusion}

The relational-cultural model suggests that human growth and development occur within relationships and toward relationships (Jordan, 2001). This theory puts isolation at the heart of human suffering and emphasizes the movement out of isolation and back into connection as the primary mode of healing (Jordan). In essence, this simple focus on connection and isolation makes the relational-cultural model potentially powerful in the healing of child neglect victims. Some maintain the presence or absence of secure relationships at the time of the neglect is the most important determinant of long-term damage (Banks, 2006). The range of reactions to neglect includes substance abuse, disconnection, PTSD, or other internalized disorders that have been undertreated in this population. However, Banks reported that while all of these reactions can be devastating, the destruction of relationships interferes most with recovery and healing.

Generally, research supports the need for a child neglect assessment instrument that embraces components of relational-cultural theory (Banks, 2006; Daniel, 2014; Hicks \& Stein, 2015; Naughton et al., 2017; Raws, 2018). In particular, because older youth may be rejected as independent and grown up, may be misdiagnosed, ignored as victimless, or deemed able to handle it, the need for such an instrument is vital to the future of this group (Raws). These youth are often left without proper assessment and treatment leading to a subpopulation of relationally and emotionally disconnected youth. The RANY will address this gap in assessment and subsequent relational-based treatment. It is a holistic self-report and caregiver assessment instrument that focuses on the elements that are fundamental to building relationally connected youth. Healthy growth and development in the face of child neglect require an understanding of the relational, social, and psychological impact of this form of maltreatment. Thus, the development of the RANY is guided by the need for a neglect-specific assessment tool that encompasses neglect elements, relationships, relational images, social/cultural connectors, and psychological disorders. It is an instrument that can lead to a change in the relational, social, and psychological approach to the neglected older youth. 


\section{References}

Banks, A. (2006). Relational therapy for trauma. Journal of Trauma Practice, 5(1), 25-47. https://doi.org/10.1300/J189v05no1_03

Becker-Weidman, A. (2009). Effects of early maltreatment on development: A descriptive study using the Vineland Adaptive Behavior Scales-II. Child Welfare, 88(2), 137-161.

Birrell, P. J., \& Freyd, J. J. (2006). Betrayal trauma: Relational models of harm and healing. Journal of Trauma Practice, 5(1), 49-63. https://doi.org/10.1300/J189vo5no1_04

Bundy-Fazioli, K., \& Delong Hamilton, T. A. (2013). A qualitative study exploring mothers' perceptions of child neglect. Child \& Youth Services, 34, 250-266. https://doi.org/10.1080/0145935X.2013.826034

Cashmore, J. (2011). The link between child maltreatment and adolescent offending: Systems neglect of adolescents. Family Matters, 89, 31-41. https://aifs.gov.au/sites/default/files/fm8gd.pdf

Child Welfare Information Gateway. (2018a). Acts of omission: An overview of child neglect. U.S. Department of Health and Human Services, Children's Bureau. https://www.acf.hhs.gov/cb/research-datatechnology/statistics-research/child-maltreatment

Child Welfare Information Gateway. (2018b). Child maltreatment 2016: Summary of key findings. U.S. Department of Health and Human Services, Children's Bureau. https://www.acf.hhs.gov/cb/research-data-technology/statistics-research/child-maltreatment

Children Services' Practice Notes for North Carolina Child Welfare Social Workers. (2013). Child neglect: Impact and interventions. 18(1), 1-9.

Comstock, D. L., Hammer, T. R., Strentzsch, J., Cannon, K., Parsons, J., \& Salazar G., II (2008). Relationalcultural theory: A framework for bridging relational, multicultural, and social justice competencies. Journal of Counseling \& Development, 86, 279-287. https://doi.org/10.1002/j.15566678.2008.tbo0510.x

Dale, A. C. (2017). Child neglect, child physical abuse, and relationships among 12-year-old girls. [Doctoral Dissertation, Walden University]. https://scholarworks.waldenu.edu/cgi/viewcontent.cgi?article $=4703 \&$ context $=$ dissertations

Daniel, B., Burgess, C., Whitfield, E., Derbyshire, D., \& Taylor, J. (2014). Noticing and helping neglected children: Messages from action on neglect. Child Abuse Review 23, 274-285. https://doi.org/10.1002/car.2339

Evans, C. B. R., \& Burton, D. L. (2013). Five types of child maltreatment and subsequent delinquency: Physical neglect as the most significant predictor. Journal of Child \& Adolescent Trauma, 6(4), 231245. https://doi.org/10.1080/19361521.2013.837567

Gaudin, J. M., Polansky, N. A., \& Kilpatrick. A. C. (1992). The child well-being scales: A field trial. Child Welfare, 71, 319-328.

Hicks, L., \& Stein, M. (2015). Understanding and working with adolescent neglect. Child \& Family Social Work, 2O, 223-233. https://doi.org/10.1111/cfs.12072

Jordan J. V. (2001) A relational-cultural model: Healing through mutual empathy. Bulletin of the Menninger Clinic, Winter 65(1), 92-103. https://doi.org/10.1521/bumc.65.1.92.18707.

Jordan, J. V. (2010). Relational cultural therapy. American Psychological Association.

Li, J., \& Julian, M. (2012). Developing relationships as the active ingredient: A unifying working hypothesis of "what works" across intervention settings. American Journal of Orthopsychiatry, 82 (2), 157-166. 
Liddle, I., \& Carter, G. (2015). Emotional and psychological well-being in children: The development and validation of the Stirling Children's Well-Being Scale. Journal of Educational Psychology in Practice, 31(2), 174-185. https://doi.org/10.1080/02667363.2015.1008409

Lyons, P., Doueck, H. J., Koster, A. J., Witzky, M. K., \& Kelly, P. L. (1999). The child well-being scales as a clinical tool and a management information system. Child Welfare, 78(2), 241-258.

Magura, S., \& Moses, B. S. (1986). Outcome measures for child welfare services. Child Welfare League of America.

National Children's Alliance. (2018). National Statistics on Child Abuse. https://www.nationalchildrensalliance.org/media-room/national-statistics-on-childabuse/\#: :text=An\%20estimated\%20678\%2C000\%20children\%20(unique,kids\%20in\%20a\%2ogive n\%20year.

Naughton, A. M., Cowley, L. E., Tempest, V., Maguire, S. A., Mann, M. K., \& Kemp, A.M. (2017). Ask me! selfreported features of adolescents experiencing neglect or emotional maltreatment: A rapid systematic review. Child: Care, Health and Development, 43(3), 348-360. https://doi.org/10.1111/cch.12440

Raws, P. (2018). Thinking about adolescent neglect A review of research on adolescent neglect focusing on identification, assessment and intervention. The Children's Society, 80 , https://www.saferchildrenyork.org.uk/Downloads/thinking about adolescent neglect reportChildrenSociety.pdf

Rivas-Drake, D., Seaton, E., Markstrom, C., Quintana, S., Syed, M., Lee, R., Schwartz, S., Umaña-Taylor, A., French, S., Yip, T. (2014). Ethnic and racial identity in adolescence: Implications for psychosocial, academic, and health outcomes. Child Development, 85, 40-57. https://doi.org/10.1111/cdev.12200

Sen, R., Lister, P. G., Rigby, P., \& Kendrick, A. (2014) Grading the graded care profile. Child Abuse Review, 23(5), 361-373.

Stowman, S. A., \& Donohue, B. (2005). Assessing child neglect: A review of standardized measures. Aggression and Violent Behavior, 10(4), 491-512. https://doi.org/10.1016/j.avb.2004.08.001

U.S. Department of Health and Human Services, Administration for Children and Families, Administration on Children, Youth and Families, Children's Bureau. (2012). Child Maltreatment 2011. http://www.acf.hhs.gov/programs/cb/research-data-technology/statistics-research/childmaltreatment

U.S. Department of Health \& Human Services, Administration for Children and Families, Administration on Children, Youth and Families, Children's Bureau. (2019). Child Maltreatment 2017. https://www.acf.hhs.gov/sites/default/files/cb/cm2017.pdf

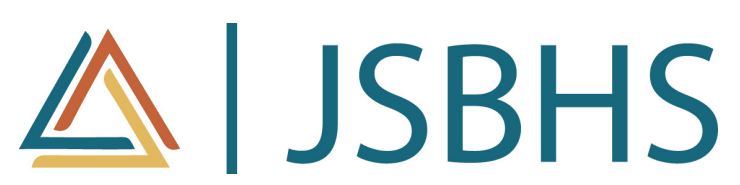

The Journal of Social, Behavioral, and Health Sciences (JSBHS), co-sponsored by the College of Health Sciences and the College of Social and Behavioral Sciences at Walden University, is a peer-reviewed, online, interdisciplinary journal focusing on theoretically-based research that addresses contemporary national and international issues. JSBHS articles include peer-reviewed research reports, brief reports, comprehensive literature reviews, books reviews, and student research. 